\title{
Evaporation rates for a coral island by field observation and simulation
}

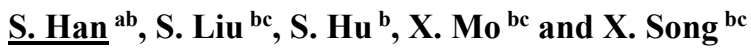 \\ ${ }^{a}$ University of Chinese Academy of Sciences, Beijing 100049, PR China, ${ }^{b}$ Key Laboratory of Water Cycle \\ and Related Land Surface Processes, Institute of Geographic Sciences and Natural Resources Research, \\ Chinese Academy of Sciences, Beijing 100101, PR China, ${ }^{c}$ College of Resources and Environment, Sino- \\ Danish Center, University of Chinese Academy of Sciences, Beijing 100049, PR China. \\ Email: liusx@igsnrr.ac.cn
}

\begin{abstract}
Evaporation in coral islands influences their limited freshwater recharge and plays an important role in coral reefs ecology protection under the background of climate changes. From June 20th to August 16th, 2018, a field experiment was carried out in Zhaoshu Island, Xisha Islands, China, using a self-made microlysimeter and pan evaporation dish. To understand the whole process of evaporations at the annual scale, we used the Penman-Monteith model and crop coefficient $(\mathrm{Kc})$ method to estimate potential evaporation (ETo) and actual evaporation (ETc) using meteorological data and leaf area index (LAI). The results show (1) ETo reached its peak value earlier than precipitation, causing island vegetations to suffer the highest water stress at the end of the dry season. (2) in the wet season, ETc rose as the precipitation increased, however, the ETo presented a tendency of slowly declining. These phenomena indicate that the vegetation could suffer from strong drought at the end of the dry season because of the maximum ETo and extended low rate of precipitation. Therefore, more attention should be paid to this period.
\end{abstract}

Keywords: Coral reef, micro-lysimeter, Penman-Monteith 


\section{INTRODUCTION}

Evapotranspiration is an important part of the water cycle for coral islands. In the Pacific region, evapotranspiration on coral islands accounts for $1 / 3$ to $1 / 2$ of the precipitation on average across a year, and in the dry season, the evapotranspiration may be greater than precipitation (Falkland 1993, White and Falkland 2010). Measurements on Niue Island in the south-central Pacific indicated that its annual precipitation was ranged from $847 \mathrm{~mm}$ to $2050 \mathrm{~mm}$, of which evapotranspiration accounted for $56-75 \%$, groundwater recharged $25-42 \%$, and runoff accounted for $0-2 \%$ (Robbins, 2013). Evapotranspiration on coral islands is different from the mainland because of the special weather conditions, hydraulic properties of soil and vegetation characteristics. Research into evaporation rates could therefore help understanding of local water cycle and help maintain a sustainable ecology of the coral island.

Coral islands evapotranspiration research is mainly divided into observational and model-based methods (Werner et al. 2017). Nullet (1987) used the Priestley-Taylor formula to show that typical Pacific island ETo ranges from 1600 to $1800 \mathrm{~mm} / \mathrm{y}$. Jocson et al. (2002) used the Penman formula to calculate ETo of the Tarawa Atoll in the Pacific Ocean $(1420 \mathrm{~mm} / \mathrm{y})$. Woodroffe and A.C.Falkland (1997) combined the Penman formula and pan evaporation data (pan coefficient is 0.8) to estimate ETo on Tarawa Atoll as $1983 \mathrm{~mm} / \mathrm{y}$ and $2048 \mathrm{~mm} / \mathrm{y}$, respectively. Falkland (1994) used penman formula and the evaporating vessel evaporation method to study Tarawa island in the central Pacific, showing that coconut trees were the main source of island water consumption, with $100 \%$ vegetation coverage and at typical tree spacing of about 8 meters prevail, coconut trees can consume $400-700 \mathrm{~mm}$ of water annually. Falkland and Woodroffe (2004) used the water-balance method to demonstrate that if all coconut trees on Tarawa island were removed, the freshwater supply would increase by $50 \%$. Roupsard et al. (2006) studied the water cycle process of Vanuatu (South Pacific) that monitored stand evapotranspiration by eddy-covariance (E), tree transpiration (T) by heat-dissipative sap flow, soil heat flux (G) and stand heat storage (J) during 3 years for a typical coconut palm row plantation of the humid tropics. The site a constant leaf area index $(\mathrm{LAI}=3)$ and a grass under-storey. On an annual time scale, E represented $40 \%$ of rainfall, T represented $68 \%$ of $\mathrm{E}$, close to the $75 \%$ of soil coverage by palms. Gingerich et al. (2017) used a numerical simulation method to simulate the Marshall Islands water budgets. When half of the Marshall Islands were simulated as being planted with high-density woody plants and a half with herbaceous plants, the groundwater recharge on the woody portion was $84 \%$ less than that on the herbaceous zone. Cozzolino et al. (2017) studied freshwater lakes in dunes on the northern coast of Italy and showed that due to the use of pine forests instead of native shrubs or bare land, intense evapotranspiration reduces subsurface storage and increases the risk of soil salinization in the region.

Currently, fieldwork on coral reef islands is limited because of the difficulties of access and maintaining instruments. Present studies are mainly focused on annual evapotranspiration, but the process of monthly evapotranspiration in a coral island still requires further investigation. The objective of this article is to analyze the relationship among ETo, ETc, and precipitation of Zhaoshu island, Xisha Islands, China, combining field observation and models to estimate time-averaged evaporation, especially at monthly scale.

\section{STUDY AERA}

Zhaoshu Island of Xisha islands is located at latitude $16^{\circ} 59.9$ north and longitude $112^{\circ} 14.7$ east. It has a tropical monsoon climate that is warm all the year with dry and wet seasons, the average annual temperature is above $26^{\circ} \mathrm{C}$, and the daily temperature variation in a year is only about $6^{\circ} \mathrm{C}$. The rainfall mainly controlled by typhoons and convective rains, with the average annual rainfall of about $1500 \mathrm{~mm}, 85 \%$ of which is concentrated in June-November (Zuo et al. 2015). Zhaoshu island is a natural coral island with an area of 0.22 $\mathrm{km}^{2}$, covered with lush vegetation distributed in a ring and band, and there are patches of beach rocks on the outside with an elevation of about $3 \mathrm{~m}$. The soil type is calcareous sand which is a marine sediment originating from coral and other creatures' debris, and has a high permeability. The water table is between 2.5 to $3.0 \mathrm{~m}$ and is influenced by the tides (Xu et al. 2014, Zhou et al. 2017).

\section{MATERIALS AND METHODS}

\subsection{Field observation methods}

A special constructed micro-lysimeter was used to observe the actual evaporation. The size of micro-lysimeter was selected by referring to the research of Sun et al. (2004). It was constructed from PVC pipe, The height of 
its inner tube is $150 \mathrm{~mm}$, the inner diameter is $101.6 \mathrm{~mm}$ and the wall thickness is $4.2 \mathrm{~mm}$. The inner diameter of its outer tube is $115.4 \mathrm{~mm}$, and the thickness is $4.8 \mathrm{~mm}$. The outer tube is fixed in the soil so that it is easy to take out and put back the inner tube without damaging the structure of the surrounding soil. An electronic balance was used to measure the evapotranspiration rate of micro-lysimeter to an accuracy of $0.01 \mathrm{~g}$, which is equivalent to the evapotranspiration amount of $0.0012 \mathrm{~mm}$ of the micro-lysimeter meter. The weighing time starts at 06:30 just after sunrise and ends at 18:30 when the sunsets.

The surface water evaporation was measured using a constructed evaporating dish. It is made from a PVC tube with an inner diameter of $200 \mathrm{~mm}$, a height of $90 \mathrm{~mm}$ and a wall thickness of $6.9 \mathrm{~mm}$. During the experiment, the evaporating dish was placed on a bracket $70 \mathrm{~cm}$ above the ground exposed to the sun. It was measured at 06:30 and 18.30 every day using an electronic balance. After measuring its weight every morning, water was added to the evaporation dish to keep water in a depth of $10 \mathrm{~mm}$.

Meteorological data were obtained from NOAA global summary of the day data, and we utilized a Chinese national weather station in another island at a distance of $20 \mathrm{~km}$ from the study site. NDVI was obtained from sentinel-2 with $10 \mathrm{~m}$ resolution using the Google Engine Editor.

\subsection{Model methods}

The estimate of ETo was done using the Penman-Monteith expression (FAO-56 1998):

$$
\lambda E T=\frac{\Delta\left(R_{n}-G\right)+\rho_{a} c_{p} \frac{\left(e_{s}-e_{a}\right)}{r_{a}}}{\Delta+\gamma\left(1+\frac{r_{s}}{r_{a}}\right)}
$$

where $R_{n}$ is the net radiation, $G$ is the soil heat flux, $\left(e_{s}-e_{a}\right)$ represents the vapor pressure deficit of the air, $\rho_{a}$ is the mean air density at constant pressure, $c_{p}$ is the specific heat of the air, $\Delta$ represents the slope of the saturation vapor pressure temperature relationship, $\gamma$ is the psychrometric constant, and $r_{s} r_{a}$ are the (bulk) surface and aerodynamic resistances.

The estimate of the actual evapotranspiration is made using the crop coefficient approach for calculating the crop evapotranspiration:

$$
E T c=K c * E T \mathrm{o}
$$

where ETc is the actual evaporation, and $K c$ is the crop coefficient. The vegetation is evergreen so we divided its growth stage into high growth stage and low growing stage which are June-November and December- next May, they correspond to the wet season and dry season respectively.

\section{RESULT}

\subsection{Model Validation}

Employing the values of ETo observed with pan (ETo_Pan), ETc was observed with the micro-lysimeter (ETc_ML) to compare with ETo simulated using the Penman-Monteith method (ETo_PM), ETc simulated using the crop coefficient method (ETo_Kc). As Figure 1 (a) shows ETo_PM appeared to be $0.8 \mathrm{~mm}$ higher than ETo_Pan on average. This may be due to the lush vegetation, but it also could indicate the simulation is accurate because of its reasonable pattern, although the differences vary considerably. Comparing ETc_ML which was measured with grasses micro-lysimeters with ETc_Kc shows that their mean differences were $0.1 \mathrm{~mm} /$ day, and it presented a great synchronism. Although there were two extra points on $28^{\text {th }}$ and $29^{\text {th }}$ June, it appears that the ETc_Kc is a suitable method and could simulate the actual evaporation in this area. 


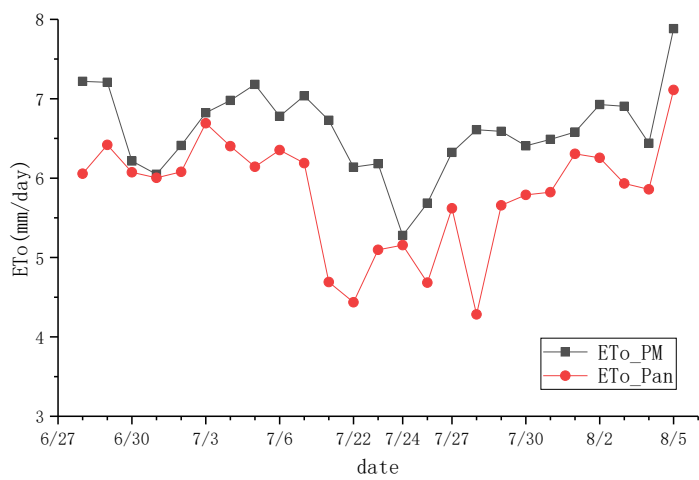

(a)

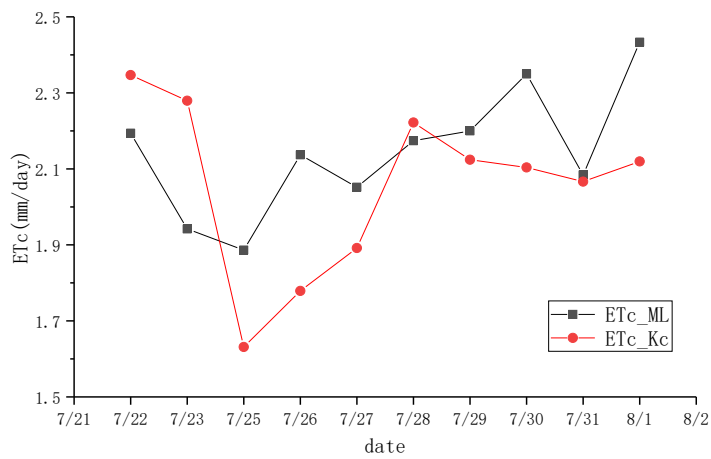

(b)

Figure 1. (a) Comparison of ETo_PM and ETo_Pan; (b) Comparison of ETc_Kc and ETc_ML.

\subsection{The relationships between precipitation and ETo}

Figure 2 indicates that the annual precipitation ranged from $850 \mathrm{~mm}$ to $1910 \mathrm{~mm}$ with large fluctuations, but the ETo stabilized near $1260 \mathrm{~mm}$. The fluctuation of annual precipitation was mainly affected by EI Niño and extremes the weather events such as typhoons, However, ETo is mainly controlled by radiation and local vegetation conditions which are similar in different years. Precipitation is larger than ETo in most years. This indicated that precipitation is recharging groundwater because there is nearly no runoff in the coral islands. However, a reversal applied in the 2015 and 2018 because of EI Niño.

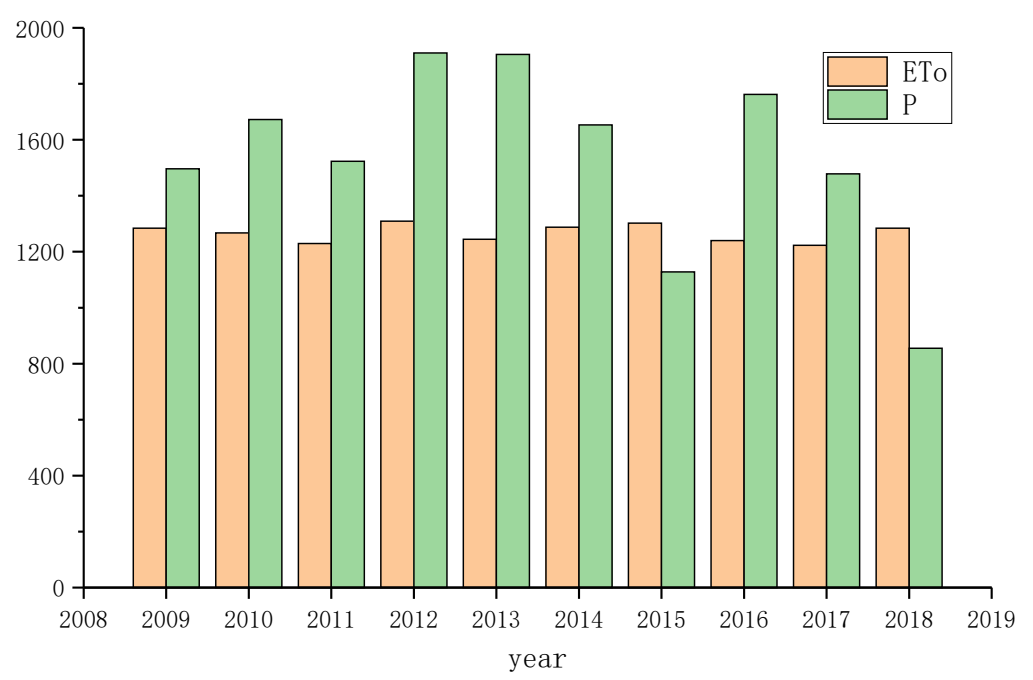

Figure 2. Variations of annual ETo and annual precipitation from 2009 to 2018.

Zhaoshu Island has one wet season and one dry season each year. Calculating the monthly average precipitation and ETo from 2015 to 2018. showed as Figure 3, the dry season was from December to May, when the precipitation was small which accounted for $19 \%$ of annual precipitation, ETo got its peak value in April. The wet season was from June to November with the precipitation reaching the maximum value in September. However, ETo deceased slightly before September and then dropped to $2.5 \mathrm{~mm}$ /day suddenly. This illustrated that the rise of precipitation could increase water recharge, but the ETo restrained the rate of evapotranspiration. 


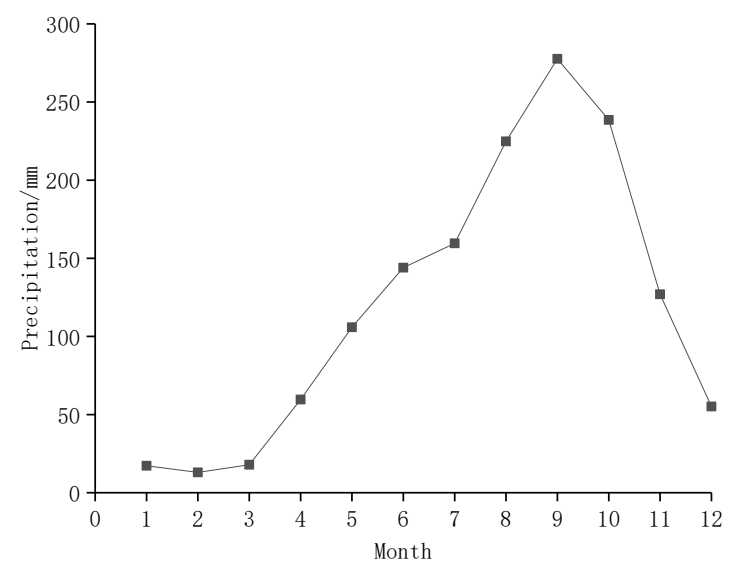

(a)

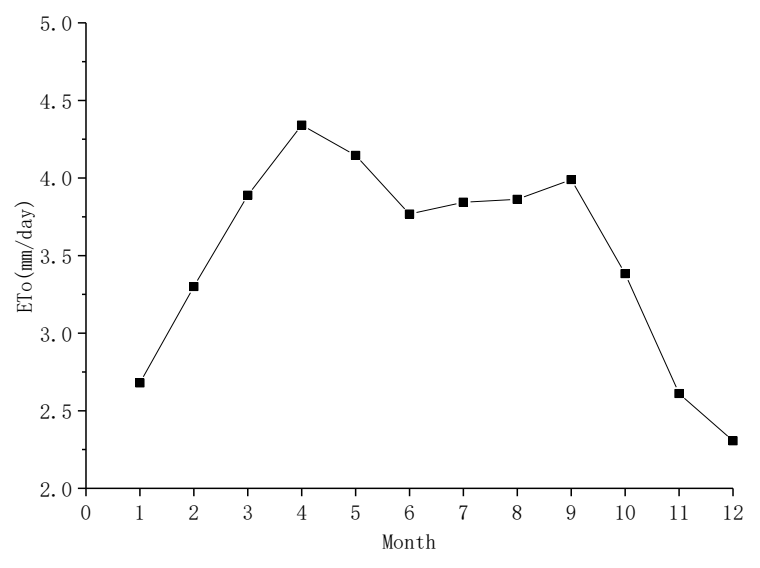

(b)

Figure 3. Monthly distribution of average precipitation and average ETo from 2015 to 2018.

\subsection{The relationships between ETc and ETo}

Figure 4 (a) shows that Kc ranged from 0.5 to 0.7 in the whole year, which increased in the wet season reaching the peak in October, then dropped suddenly and fluctuated at a low level in the dry season. The ETo ranged from $2 \mathrm{~mm}$ /day to $4.5 \mathrm{~mm}$ /day, ETc ranged from 1.3 to $2.5 \mathrm{~mm}$ /day. In the wet season, ETo decreases slowly which was different from the variation tendency of precipitation, but the actual evaporation increases slowly contrary to ETo (figure4 (b) ) owing to the increase of Kc. This represented that the distribution of ETc is closely related with $\mathrm{Kc}$, but influenced by precipitation and ETo.

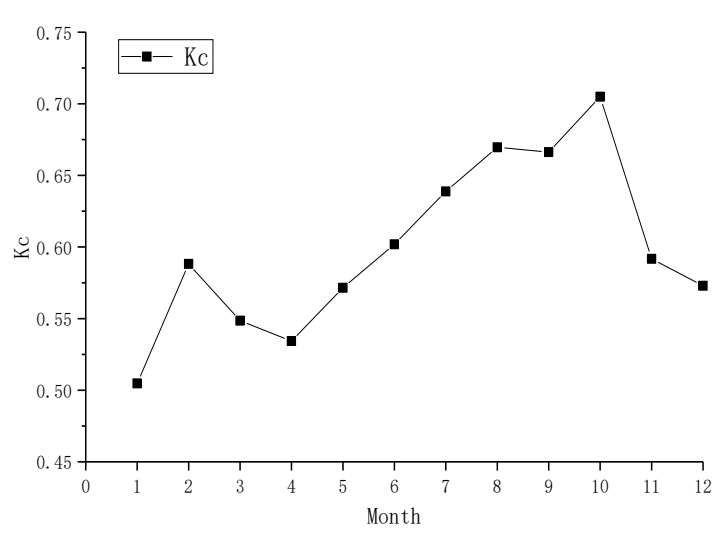

(a)

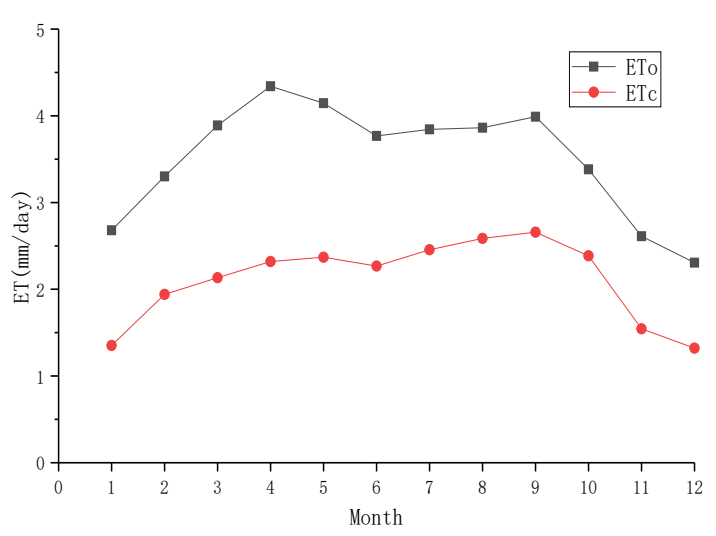

(b)

Figure 4. (a) Monthly distribution of average ETo, ETc from 2015 to 2018; (b) the value of monthly Kc from 2015 to 2018 .

\section{CONCLUSION}

ETo, ETc, and precipitation have different temporal distribution characteristics. ETo reached its peak value in April, versus the precipitation was just beginning to increase at the same time when is the end of the dry season. ETc raised with the increase of precipitation and reached its peak value in October, although the ETo showed a decreasing tendency. These phenomena indicate that precipitation delays ETo which can result in vegetation suffering from severe drought at the end of the dry season in the coral island, Further research is needed on this problem. 


\section{ACKNOWLEDGMENTS}

This project is supported by the Strategic Priority Research Program of the Chinese Academy of Sciences, Grant No.XDA13010303. The authors acknowledge helps of companions of other brother institutes and Island fishermen in the process of field observations. The helpful comments of reviewers led to significant improvement in this article.

\section{REFERENCES}

Cozzolino, D., N. Greggio, M. Antonellini and B. M. S. Giambastiani (2017). "Natural and anthropogenic factors affecting freshwater lenses in coastal dunes of the Adriatic coast." Journal of Hydrology 551: 804818.

Falkland, A. (1994). "Climate, Hydrology, and Water Resources of the Cocos (Keeling) Islands."

Falkland, A. and C. Woodroffe (2004). Geology and hydrogeology of Tarawa and Christmas Island, Kiribati. Developments in sedimentology, Elsevier. 54: 577-610.

Falkland, A. C. (1993). "Hydrology and water management on small tropical islands." IAHS PUBLICATION: 263-263.

FAO-56 (1998). "Crop evapotranspiration - Guidelines for computing crop water requirements - FAO Irrigation and drainage paper 56."

Gingerich, S. B., C. I. Voss and A. G. Johnson (2017). "Seawater-flooding events and impact on freshwater lenses of low-lying islands: Controlling factors, basic management and mitigation." Journal of Hydrology 551: 676-688.

Jocson, J. M. U., J. W. Jenson and D. N. Contractor (2002). "Recharge and aquifer response: Northern Guam Lens Aquifer, Guam, Mariana Islands." 260 (1-4) : 231-254.

Nullet, D. (1987). "WATER BALANCE OF PACIFIC ATOLLS 1." JAWRA Journal of the American Water Resources Association 23 (6) : 1125-1132.

Robins, N. (2013). "A review of small island hydrogeology: progress (and setbacks) during the recent past." Quarterly Journal of Engineering Geology and Hydrogeology 46 (2) : 157-165.

Roupsard, O., J.-M. Bonnefond, M. Irvine, P. Berbigier, Y. Nouvellon, J. Dauzat, S. Taga, O. Hamel, C. Jourdan and L. Saint-André (2006). "Partitioning energy and evapo-transpiration above and below a tropical palm canopy." Agricultural and Forest Meteorology 139 (3-4) : 252-268.

Sun, H. Y., C. M. Liu, Y. Q. Zhang and X. Y. Zhang (2004). "Study on soil evaporation by using microlysimeter." Journal of Hydraulic Engineering 35 (8) : 114-118.

Werner, A. D., H. K. Sharp, S. C. Galvis, V. E. Post and P. Sinclair (2017). "Hydrogeology and management of freshwater lenses on atoll islands: Review of current knowledge and research needs." Journal of Hydrology 551: 819-844.

White, I. and T. Falkland (2010). "Management of freshwater lenses on small Pacific islands." Hydrogeology Journal 18 (1) : 227-246.

Woodroffe, C. D. and A.C.Falkland (1997). "Geology and hydrogeolgy of the cocos (Keeling) islands." development in Sedimentology.

Xu, J., D. Zhao, J. Chnaes, B. Geomorphology and R. B. Construction (2014). "Review of coral reef ecosystem remote sensing." Acta Ecologica Sinica 34 (1) : 19-25.

Zuo, X., F. Su, W. Wu, Z. Chen and W. Shi (2015). "Spatial and temporal variability of thermal stress to China's coral reefs in South China Sea." Chinese geographical science 25 (2) : 159-173.

Zhou,C. F,Z. W,Y. and F,X (2017) , "Development and utilization of freshwater lenses in coral reef.", Chongqing University Press[周从直, 方振东, 魏营 and 冯孝杰 (2017). 珊瑚岛礁淡水透镜体的开发 利用, 重庆大学出版社.] 